\title{
Peak exercise capacity prediction from a submaximal exercise test in coronary artery disease patients
}

\section{Arto J. Hautala ${ }^{*}$, Antti M. Kiviniemi ${ }^{1,2}$, Jaana J. Karjalainen ${ }^{1,2}$, Olli-Pekka Piira ${ }^{2}$, Samuli Lepojärvi ${ }^{2}$, Timo Mäkikallio² ${ }^{2}$ Heikki V. Huikuri' ${ }^{2}$ and Mikko P. Tulppo ${ }^{1,2}$}

${ }^{1}$ Department of Exercise and Medical Physiology, Verve Research, Oulu, Finland

${ }^{2}$ Department of Internal Medicine, Institute of Clinical Medicine, University of Oulu, Oulu, Finland

\section{Edited by:}

Kari Kalliokoski, University of Turku, Finland

Reviewed by:

Arkady Rutkovskiy, University of

Oslo, Norway

Ilkka H. A. Heinonen, University of

Turku, Finland

Andreas Bergdahl, Concordia

University, Canada

*Correspondence:

Arto J. Hautala, Department of Exercise and Medical Physiology, Verve Research, Kasarmintie 13, PO Box 404, Fl-90101 Oulu, Finland e-mail: arto.hautala@verve.fi
The purpose of this study was to determine whether a rating of perceived exertion scale (RPE) obtained during submaximal exercise could be used to predict peak exercise capacity (MET peak) in coronary artery disease (CAD) patients. Angiographically documented CAD patients ( $n=124,87 \%$ on $\beta$ blockade) completed a symptom-limited peak exercise test on a bicycle ergometer, reporting RPE values at every second load on a scale of 6-20. Regression analysis was used to develop equations for predicting $\mathrm{MET}_{\text {peak. }}$. We found that submaximal METs at a workload of 60/75 W (for women and men, respectively) and the corresponding RPE (METs/RPE ratio) was the most powerful predictor of $\mathrm{MET}_{\text {peak }}(r=0.67, p<0.0001)$. The final model included the submaximal METs/RPE ratio, body mass index (BMI), sex, resting heart rate, smoking history, age, and use of a $\beta$ blockade ( $r=0.86, p<0.0001$, SEE 0.98 METs). These data suggest that $\mathrm{RPE}$ at submaximal exercise intensity is related to $\mathrm{MET}_{\text {peak }}$ in CAD patients. The model based on easily measured variables at rest and during "warm-up" exercise can reasonably predict absolute $\mathrm{MET}_{\text {peak }}$ in patients with CAD.

Keywords: exercise capacity, rating of perceived exertion, exercise testing, cardiac patients, prediction

\section{INTRODUCTION}

A large volume of data confirms the inverse dose-response relationship between peak exercise capacity $\left(\mathrm{MET}_{\text {peak }}\right)$ and allcause mortality in both male and female coronary artery disease (CAD) patients irrespective of the use of $\beta$-blocking medication (Kavanagh et al., 2002, 2003), including patients with a history of myocardial infarction, coronary artery bypass grafting $(\mathrm{CABG})$, percutaneous coronary intervention $(\mathrm{PCI})$, and chronic heart failure (Perk et al., 2012). Although being able to measure $\mathrm{MET}_{\text {peak }}$ by the "golden standard" method of a direct incremental symptom-limited peak exercise test, it may not be feasible in everyday clinical settings for rehabilitation or in assessment of functional capacity in CAD patients. Due to increasing constraints of time, equipment, patient safety and personnel needed to carry out these tests, practical applications are typically submaximal laboratory or field tests; e.g., a six-minute walking test (Lipkin et al., 1986) is recommended for CAD patients (Wijns et al., 2010). However, several adequate submaximal tests that estimate $\mathrm{MET}_{\text {peak }}$ are based on nomograms which predict $\mathrm{MET}_{\text {peak }}$, assuming a more or less linear increase in heart rate simultaneously with increasing workload and oxygen uptake

Abbreviations: ACEI, angiotensin conversion enzymes inhibitor; AMI, acute myocardial infarction; ARB, angiotensin receptor blocker; ACEI/ARB, patients using at least one of them; BMI, body mass index; BP, blood pressure; CABG, coronary artery bypass grafting; CCS, Canadian Cardiovascular Society angina classification; HbAlc, glycated hemoglobin; HDL, high-density lipoprotein; HR, heart rate; LDL, low-density lipoprotein; LVEF, left ventricular ejection fraction; LVMI, left ventricular mass index; METs, metabolic equivalents; $n$, number of subjects; NSTEMI, non-ST segment elevation myocardial infarction; PCI, percutaneous coronary intervention; T2D, type 2 diabetes; STEMI, ST segment elevation myocardial infarction.
(Astrand and Ryhming, 1954; WHO, 1968). These tests are able to predict $\mathrm{MET}_{\text {peak }}$ in healthy subjects but not in CAD patients due to the use of medication, particularly $\beta$ blockades. Therefore, accurate predictive estimates for $\mathrm{MET}_{\text {peak }}$ in CAD patients are warranted.

The ratings of perceived exertion (RPE) scale (Eston and Williams, 1988) is widely accepted for obtaining a subjective estimate of work intensity and as a means of quantifying, monitoring, and evaluating exercise intensity not only in healthy subjects, but also in CAD patients (Pollock and Pels, 1984; Corra et al., 2010; Scherr et al., 2013). The practical use of RPE for exercise prescription also in patients with $\beta$ blockades is well documented (Eston and Connolly, 1996; Goss et al., 2011). Therefore, we hypothesized that RPE during submaximal exercise can be used to predict $\mathrm{MET}_{\text {peak }}$ in CAD patients. The purpose of this study was firstly to develop an equation for predicting $\mathrm{MET}_{\text {peak }}$ using assessment of RPE during submaximal exercise in CAD patients, and secondly to validate the developed model and estimate the reproducibility of the model in an independent sample of CAD patients.

\section{MATERIALS AND METHODS}

The patients in the test group ( $n=124,27$ women) belong to a larger Innovation to Reduce Cardiovascular Complications of Diabetes at the Intersection study (ARTEMIS) taking place in the Division of Cardiology at Oulu University Hospital (Oulu, Finland) and the Department of Exercise and Medical Physiology at Verve (Oulu, Finland). The ARTEMIS study is registered at ClinicalTrials.gov, Record 1539/31/06. In addition, we recruited from Oulu University Hospital an independent sample of volunteer CAD patients who had suffered acute coronary syndrome to 
serve as the validation group ( $n=42,12$ women) and to test the developed equation as a predictor of MET $_{\text {peak. The patients in }}$ the validation group belong to a larger Effectiveness of Exercise Cardiac Rehabilitation study (EFEX-CARE) taking also place in the above mentioned institutions. The EFEX-CARE study is registered at ClinicalTrials.gov, Record NCT01916525. Demographic characteristics of the study population are presented in Table $\mathbf{1}$. The subjects were not allowed to eat or to drink coffee for $3 \mathrm{~h}$ before the tests. Strenuous physical activity and alcohol consumption were prohibited on the day of the tests and the preceding day. The study was performed according to the Declaration of Helsinki, the local research ethics committee of the Northern Ostrobothnia Hospital District approved the protocol, and all the subjects gave their written informed consent.

All the patients were diagnosed as having CAD, which had been documented previously by coronary angiography. In recruiting the $\mathrm{CAD}$ patients, the following exclusion criteria were adhered: advanced age ( $>75$ years), body mass index (BMI) $>40 \mathrm{~kg} / \mathrm{m}^{2}$, NYHA class III or IV, left ventricular ejection fraction $(\mathrm{LVEF})<40 \%$, scheduled cardiac revascularization therapy, unstable angina pectoris, severe peripheral atherosclerosis, or inability to perform an exercise stress test, e.g., due to musculoskeletal problems. Type 2 diabetes (T2D) was verified according to the current criteria (Spies et al., 2005). Left ventricular systolic function was assessed using 2-D echocardiography (Vivid 7, GE Healthcare, Wauwatosa, WI, USA). Blood samples were obtained for analysis of blood lipids, plasma glucose, and glycated hemoglobin (HbAlc) levels (Oulu University Hospital, Oulu, Finland).

The following protocol was performed in the Department of Exercise and Medical Physiology at Verve (Oulu, Finland). Blood pressure was measured (average of two measurements) in a supine position after a 10 -min resting period (Tango, Sun-Tech, Raleigh, NC, USA). The patients performed an incremental symptom-limited peak exercise test on a bicycle ergometer (Monark Ergomedic 839 E, Monark Exercise AB, Vansbro, Sweden) for assessment of $\mathrm{MET}_{\text {peak }}$. MET $\mathrm{T}_{\text {peak }}$ was used as an outcome of maximal exercise capacity, since measurement of peak oxygen consumption is not applied as daily routine in hospital. One metabolic equivalent (MET) is the rate of energy expenditure at rest (approximately $1 \mathrm{kcal}$ per kilogram of body weight per hour), which equates to oxygen consumption approximately $3.5 \mathrm{ml} / \mathrm{kg}$ of body weight per minute for an average adult (Jette et al., 1990). The test was started at 30 Watts (W) and the work rate was increased by $15 \mathrm{~W}$ in men and $10 \mathrm{~W}$ in women every minute until voluntary exhaustion or ST segment depression $>0.2 \mathrm{mV}$ in electrocardiography (ECG). Prior to performing the exercise test, the RPE scale was explained to each participant by trained practitioners (Borg, 1982). RPE values were asked in the $15 \mathrm{~s}$ before the end of every second workload on a scale of $6-$ 20 (Borg, 1970). MET $_{\text {peak }}$ was calculated from the mean workload during the last minute of the test. A 15-lead ECG (GE Healthcare, CAM-14, Freiburg, Germany) was taken when the patients sat $1 \mathrm{~min}$ on a bicycle without speaking, during the exercise and $10 \mathrm{~min}$ after the exercise in a supine position.

After the predictive model was developed, we applied the equation to a seven-minute submaximal testing procedure with a
Table 1 | Demographic characteristics of study populations.

\begin{tabular}{|c|c|c|c|}
\hline & $\begin{array}{l}\text { Test, } \\
n=124\end{array}$ & $\begin{array}{l}\text { Validation, } \\
n=42\end{array}$ & $p$-value \\
\hline Patients with T2D & $69(56 \%)$ & $11(26 \%)$ & 0.001 \\
\hline $\operatorname{Sex}(M / F)$ & $\begin{array}{l}97(78 \%) / \\
27(22 \%)\end{array}$ & $\begin{array}{l}30(71 \%) / \\
12(29 \%)\end{array}$ & 0.402 \\
\hline Age, years & $62 \pm 5$ & $60 \pm 10$ & 0.105 \\
\hline Height, m & $1.71 \pm 0.8$ & $1.70 \pm 0.9$ & 0.668 \\
\hline Weight, kg & $83 \pm 15$ & $81 \pm 18$ & 0.435 \\
\hline $\mathrm{BMI}, \mathrm{kg} / \mathrm{m}^{2}$ & $28.3 \pm 4.1$ & $27.7 \pm 4.6$ & 0.391 \\
\hline Waist-hip ratio & $0.99 \pm 0.11$ & $0.99 \pm 0.15$ & 0.924 \\
\hline Systolic BP, mmHg & $146 \pm 21$ & $138 \pm 22$ & 0.040 \\
\hline Diastolic BP, mmHg & $80 \pm 10$ & $76 \pm 9$ & 0.053 \\
\hline Current smokers & $13(10 \%)$ & $8(19 \%)$ & 0.180 \\
\hline Depression score & $5.0 \pm 5.0$ & $5.3 \pm 5.4$ & 0.755 \\
\hline \multicolumn{4}{|l|}{ HISTORY OF AMI } \\
\hline NSTEMI & $40(32 \%)$ & $19(45 \%)$ & 0.262 \\
\hline STEMI & $24(19 \%)$ & $11(26 \%)$ & 0.384 \\
\hline \multicolumn{4}{|l|}{ REVASCULARIZATION } \\
\hline $\mathrm{PCl}$ & $73(59 \%)$ & $32(76 \%)$ & 0.063 \\
\hline CABG & $27(22 \%)$ & $2(5 \%)$ & 0.010 \\
\hline \multicolumn{4}{|l|}{ CARDIAC FUNCTION } \\
\hline LVEF, \% & $66 \pm 8$ & $65 \pm 7$ & 0.366 \\
\hline LVMI & $101 \pm 23$ & $102 \pm 23$ & 0.804 \\
\hline CCS class & $1.2 \pm 0.4$ & $1.3 \pm 0.5$ & 0.237 \\
\hline \multicolumn{4}{|l|}{ PEAK EXERCISE TEST } \\
\hline Rest HR, bpm & $59 \pm 9$ & $60 \pm 8$ & 0.700 \\
\hline Peak HR, bpm & $130 \pm 19$ & $132 \pm 19$ & 0.665 \\
\hline Peak METs & $7.1 \pm 1.9$ & $7.1 \pm 2.0$ & 0.941 \\
\hline Estimated peak mets & $7.2 \pm 1.6$ & $7.2 \pm 1.7$ & 0.788 \\
\hline \multicolumn{4}{|l|}{ LABORATORY ANALYSES } \\
\hline $\mathrm{HbA} 1 \mathrm{c}, \%$ & $6.3 \pm 0.8$ & $6.1 \pm 1.1$ & 0.151 \\
\hline Fasting plasma glucose, $\mathrm{mmol} / \mathrm{l}$ & $6.3 \pm 1.4$ & $5.7 \pm 1.1$ & 0.021 \\
\hline Total cholesterol, mmol/l & $4.0 \pm 0.8$ & $4.0 \pm 0.9$ & 0.609 \\
\hline HDL cholesterol, mmol/l & $1.2 \pm 0.3$ & $1.3 \pm 0.3$ & 0.731 \\
\hline LDL cholesterol, mmol/l & $2.3 \pm 0.6$ & $2.4 \pm 0.8$ & 0.154 \\
\hline Triglycerides, mmol/l & $1.5 \pm 0.9$ & $1.5 \pm 0.7$ & 0.999 \\
\hline \multicolumn{4}{|l|}{ MEDICATION } \\
\hline Oral antidiabetics & $57(46 \%)$ & $10(24 \%)$ & 0.012 \\
\hline Insulin & $10(8 \%)$ & $4(10 \%)$ & 0.755 \\
\hline Beta blockers & $108(87 \%)$ & $35(83 \%)$ & 0.606 \\
\hline ACEI/ARB & $74(60 \%)$ & $30(71 \%)$ & 0.200 \\
\hline Lipid lowering drugs & $114(92 \%)$ & $40(95 \%)$ & 0.732 \\
\hline Anticoagulants & $121(98 \%)$ & $41(98 \%)$ & 0.989 \\
\hline Calcium antagonists & $26(21 \%)$ & 7 (17\%) & 0.658 \\
\hline Nitrates & $29(23 \%)$ & $11(26 \%)$ & 0.683 \\
\hline Diuretics & $38(31 \%)$ & 8 (19\%) & 0.167 \\
\hline
\end{tabular}

bicycle (Monark 939E, Monark Exercise AB, Vansbro, Sweden). Then we requested the patients in the validation group to visit our laboratory at Verve 1 day before the measurement of $\mathrm{MET}_{\text {peak }}$ to perform a seven-minute submaximal test. Furthermore, we asked the same patients to visit our laboratory 1 week after the initial visit to perform submaximal test again to assess the reproducibility of test. In the laboratory, first the patients sat $1 \mathrm{~min}$ 
on a bicycle without speaking and their average resting heart rate (Polar Electro, Kempele, Finland) was measured and recorded on a Smart Card (HUR Oy, Kokkola, Finland). Then they started cycling at $30 \mathrm{~W}$ for women and $50 \mathrm{~W}$ for men. As during $\mathrm{MET}_{\text {peak }}$ testing, the RPE scale was explained to each participant. In the $15 \mathrm{~s}$ before the end of every one-minute workload the RPE value was asked on a scale of 6-20 and recorded on the Smart Card. Based on the reported RPE after each minute, workload was automatically adjusted so that the given RPE value would be 13 at the end of 5 min of cycling. For example, if RPE after the first minute was 12 , the second workload increased automatically by $5 \mathrm{~W}$ to have an RPE of 13 after the second minute. Finally, after the 5-minute "warm up," the patients sat one more minute on the bicycle without speaking and their average recovery heart rate was measured and recorded on the Smart Card. Then the collected data were uploaded to a computer for calculation of predicted $\mathrm{MET}_{\text {peak }}$ (HUR Smart Card Software, HUR Oy, Kokkola, Finland).

Data normality was confirmed with the Kolmogorov-Smirnov goodness-of-fit test. Differences between the test and validation groups were analyzed by using independent-samples $t$ tests and chi-square tests. The data from the $\mathrm{MET}_{\text {peak }}$ test were used to develop equations for estimating $\mathrm{MET}_{\text {peak }}$ using stepwise linear regression analysis. All the significant demographic, medication, laboratory, leisure-time physical activity collected with the questionnaire and echocardiographic variables from Spearman's correlation analyses and $t$ tests were included in the linear regression analyses if their $p$-values were $<0.05$ to find the predictors that maximized the $R$-value. The following parameters were used to yield the best predictive equation: age, sex, BMI, hip and waist size, smoking history, use of $\beta$ blockade, T2D, heart rate before cycling, and submaximal METs at a workload of 60/75 W (for women and men, respectively) and corresponding RPE (METs/RPE ratio). The METs/RPE ratio was defined considering body weight and resting energy expenditure as follows: $[(60 / 75 \mathrm{~W} \times 12+3.5 \times$ body weight $) /(3.5 \times$ body weight $)]$ (Adams, 1990; ACSM, 1995).

The prediction of $\mathrm{MET}_{\text {peak }}$ was compared with the measured $\mathrm{MET}_{\text {peak }}$ in both the test and validation groups using linear regression analysis and standard error of the estimate (SEE). A Bland-Altman analysis of measurement differences plotted against mean values was used to assess the degree of agreement (Bland and Altman, 1986) and to estimate the reproducibility of the developed submaximal test. The statistical analyses were performed using SPSS software, version 19.0 (SPSS Inc., Chicago, USA). A $p$-value $<0.05$ was considered statistically significant.

\section{RESULTS}

Table 1 presents the demographic characteristics as well as the measured and estimated MET $_{\text {peak }}$ values in both populations. The groups did not differ in measured or estimated measured $\mathrm{MET}_{\text {peak }}$. There were more T2D patients, higher systolic blood pressure, and more revascularization by CABG in the test group than in the validation group $(p=0.001, p=0.040$, and $p=$ 0.010 , respectively). Accordingly, fasting plasma glucose was higher and there were more oral antidiabetic users in the test group than in the validation group $(p=0.021$ and $p=0.012$, respectively).
During the measurement of $\mathrm{MET}_{\text {peak }}$ in the test group, submaximal METs at a workload of $60 / 75 \mathrm{~W}$ (55 $\pm 15 \%$ of measured $\left.\mathrm{W}_{\text {peak }}\right)$ was $4.0 \pm 0.5\left(59 \pm 12 \%\right.$ of measured $\left.\mathrm{MET}_{\text {peak }}\right)$ and the corresponding RPE was $11.8 \pm 2.1$. The submaximal $\mathrm{METs} / \mathrm{RPE}$ ratio was the most powerful predictor of $\mathrm{MET}_{\text {peak }}$ $(r=0.67, p<0.0001)$ explaining $44 \%$ of the variability in $\mathrm{MET}_{\text {peak }}$. The final stepwise regression model correlated strongly with that of $\mathrm{MET}_{\text {peak }}$ after including the parameters in the following order: submaximal METs/RPE ratio, BMI, sex, heart rate before cycling, smoking history, age, and use of $\beta$ blockade $(r=0.86$, SEE 0.98 METs, $p<0.0001$, Figure 1A). The following best predictive equation explained $74 \%$ of the variability in $\mathrm{MET}_{\text {peak }}$ : $16.047+6.227$ (submaximal/RPE ratio) -0.178 $(\mathrm{BMI})+1.412(\mathrm{sex})-0.057$ (heart rate before cycling) -0.603 (smoking history) -0.048 (age) -0.605 (use of $\beta$ blockade) The mean difference between actual and predicted $\mathrm{MET}_{\text {peak }}$ was $0.09 \pm 1.00$ METs. The Bland-Altman plot found $94 \%$ of the data points within the limits of agreement in the test group (Figure 2A).

$\mathrm{MET}_{\text {peak }}$ values collected from the seven-minute submaximal testing procedure showed a strong association with the measured MET $_{\text {peak }}(r=0.77, p<0.0001$, SEE 1.38 METs, Figure 1B $)$ The mean difference between actual and predicted MET $_{\text {peak }}$ was $0.04 \pm 1.37$ METs. In the validation group, $98 \%$ of the data points fell within the limits of agreement (Figure 2B). The difference among two measurements of METs in the case of 26 patients, who

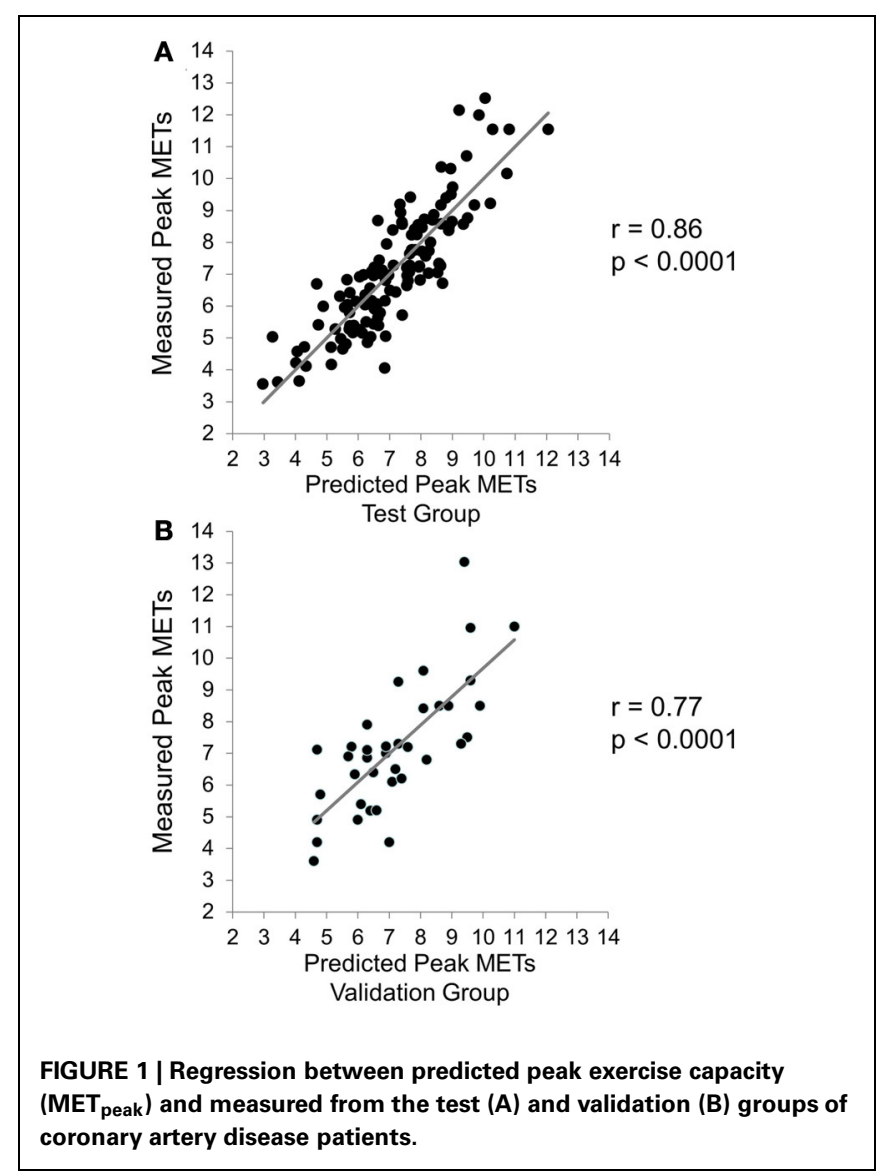



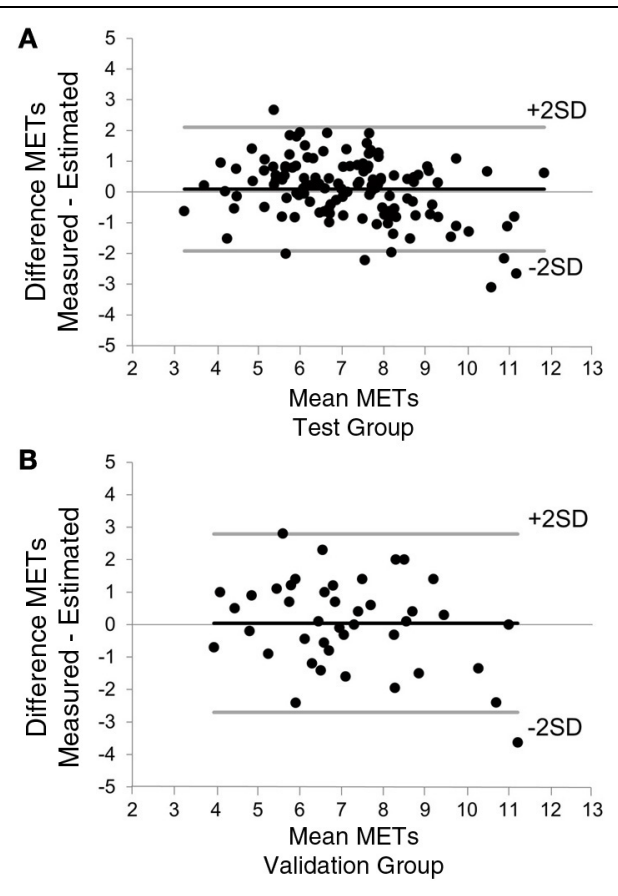

FIGURE 2 | Bland-Altman plot for predicted and measured MET peak $_{\text {in }}$ both test (A) and validation (B) groups. The bold black lines indicate the mean difference between measured and predicted $\mathrm{MET}_{\text {peak }}$ and the bold gray lines indicate the $95 \%$ limits of agreement $( \pm 2 S D$ ).

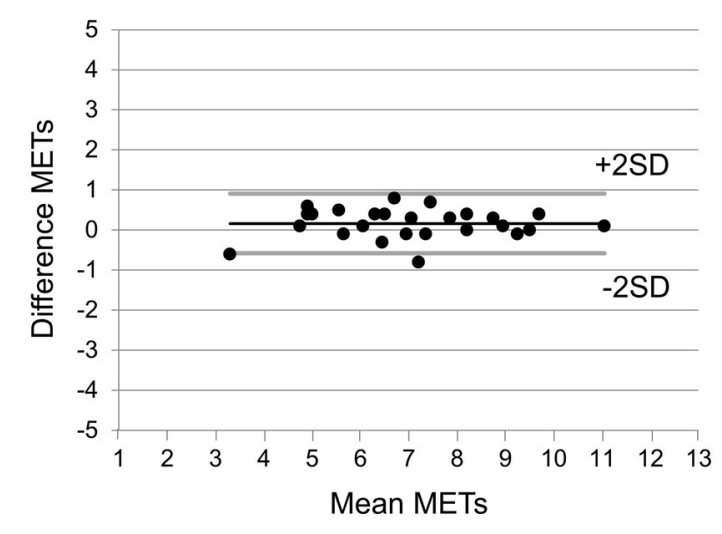

FIGURE 3 | Differences among two measurements performed on each of 26 patients as a function of their mean values for METs.

were able to participate the reproducibility study, are plotted as a function of each subject's mean value $(r=0.98, p<0.0001$, SEE 0.38 METs, Figure 3).

\section{DISCUSSION}

This study showed that RPE at submaximal exercise intensity is related to measured $\mathrm{MET}_{\text {peak }}$ in CAD patients. The data support the view that a regression model based on easily measured variables at rest and during "warm-up" exercise can be used to predict $\mathrm{MET}_{\text {peak }}$ in patients with CAD in whom a peak exercise test may not be feasible, and in repeated assessments of exercise capacity after therapeutic interventions, e.g., during rehabilitation programs, even on a weekly or monthly basis.

Borg's RPE scale is a widely used psycho-physical tool for subjectively assessing work intensity during exercise. It is also well documented that the RPE scale can be used to increase the accuracy of monitoring and the prescription of exercise intensity in the cardiac population using $\beta$ blockade therapy (Pollock and Pels, 1984; Eston and Connolly, 1996; Goss et al., 2011). In the present study we found that a submaximal METs/RPE ratio where an RPE value of approximately 12 was reached at an intensity of $60 / 75 \mathrm{~W}$ was associated most strongly with the measured MET $_{\text {peak. }}$. We decided to use a target RPE of 13 at the end of $5 \mathrm{~min}$ of cycling in the developed submaximal testing procedure because it is well in line with the finding that an RPE of 14 might indicate fatigue if an incremental treadmill test is continued in CAD patients using $\beta$ blockades (Goss et al., 2011). Furthermore, according to the latest study by Scherr et al., training intensities corresponding to an RPE range of 11-13 ("fairly light" to "somewhat hard") should be recommended for CAD patients (Scherr et al., 2013). Since safety during exercise testing is very important, we feel the developed and validated submaximal test in this study meets these demands appropriately, as well.

A 6-min walking test is a much-used, safe, and well-tolerated method for assessing exercise capacity in cardiac patients (Gayda et al., 2004; Wijns et al., 2010) and it also has prognostic value in predicting cardiovascular events in CAD patients (Beatty et al., 2012; Cacciatore et al., 2012). When the results of the walking test are compared with measured peak exercise capacity expressed as peak oxygen consumption in cardiac patients, the correlation values have varied from 0.58 to 0.69 , giving an SEE normalized by mean peak oxygen consumption from 21 to 28\% (Cahalin et al., 1996; Faggiano et al., 1997; Zugck et al., 2000; Opasich et al., 2001). In the present study, we found that the developed submaximal exercise test correlated from 0.77 to 0.86 with the measured MET $_{\text {peak, indicating an }}$ SEE from 14 to $19 \%$. Bland-Altman analysis showed that only a few values fell outside the 95\% limits of agreement, which suggests a good agreement between the actual and estimated $\mathrm{MET}_{\text {peak }}$ values. Furthermore, repeated tests performed for the validation group showed that developed test model is highly reproducible, which emphasize the use of this test as an individual monitoring tool for exercise capacity. Taken together, the present data support the concept that the estimated $\mathrm{MET}_{\text {peak }}$ values obtained from a submaximal exercise test are sufficiently accurate, as they provide also an excellent fit with published results.

It should be noted that the test and validation groups differed from each other in certain demographic characteristics, e.g., there were more revascularizations by CABG and a greater tendency toward higher blood pressure in the test group than in the validation group. Potentially, the differences are explained by the fact that there was more T2D in the test group. The patients in the test group belong to a larger ARTEMIS study, where the aim is to gather two groups of patients; CAD patients with and without T2D. The patients in the separate validation 
group were volunteers who had suffered from acute coronary syndrome. However, T2D was not related to measured MET $\mathrm{T}_{\text {peak }}$ and it was not included in the predictive equation. Still, it remains speculative if the minor discrepancy in the accuracy of the test between groups (SEE 14 vs. 19\%) is partly explained either by the differences in demographic parameters or the implemented submaximal testing procedure or both.

Based on the findings of the present study, the proposed submaximal testing procedure can be useful for CAD patients also in terms of motivation for physical activity and exercise training, since the assessment of MET $_{\text {peak }}$ is available during the "warmup" of a single exercise session and no extra time for exercise testing is needed. However, the ability of our test to follow changes in $\mathrm{MET}_{\text {peak }}$ during rehabilitation needs to be confirmed in further studies. Another advantage of the developed test is the use of guided self-regulated moderate exercise intensity expressed as target RPE 13 at the end of the "warm up." In this regard, a certain learning effect of subjective feeling of moderate-intensity exercise could be used to facilitate a transition from a supervised to a selfguided exercise program and hopefully to serve as a contributing factor for better adherence to a physical activity program. Finally,

\section{REFERENCES}

ACSM. (1995). ACSM's Guidelines for Exercise Testing and Prescription. Philadelphia, PA: Lippicott Williams and Wilkins.

Adams, G. (1990). Exercise Physiology Laboratory Manual. Dubuque, IA: Wm. C. Brown. Publisher.

Astrand, P. O., and Ryhming, I. (1954). A nomogram for calculation of aerobic capacity (physical fitness) from pulse rate during sub-maximal work. J. Appl. Physiol. 7, 218-221.

Beatty, A. L., Schiller, N. B., and Whooley, M. A. (2012). Six-minute walk test as a prognostic tool in stable coronary heart disease: data from the heart and soul study. Arch. Intern. Med. 172, 1096-1102. doi: 10.1001/archinternmed.2012.2198

Bland, J. M., and Altman, D. G. (1986). Statistical methods for assessing agreement between two methods of clinical measurement. Lancet 1, 307-310. doi: 10.1016/S01406736(86)90837-8

Borg, G. (1970). Perceived exertion as an indicator of somatic stress. Scand. J. Rehabil. Med. 2, 92-98.

Borg, G. A. (1982). Psychophysical bases of perceived exertion. Med. Sci. Sports Exerc. 14, 377-381. doi: $\quad 10.1249 / 00005768-1982$ 05000-00012

Cacciatore, F., Abete, P., Mazzella, F., Furgi, G., Nicolino, A., Longobardi, G., et al. (2012). Six-minute walking test but not ejection fraction predicts mortality in elderly patients undergoing cardiac rehabilitation following coronary artery bypass grafting. Eur. J.
Prev. Cardiol. 19, 1401-1409. doi: 10.1177/1741826711422991

Cahalin, L. P., Mathier, M. A., Semigran, M. J., Dec, G. W., and Disalvo, T. G. (1996). The six-minute walk test predicts peak oxygen uptake and survival in patients with advanced heart failure. Chest 110, 325-332. doi: 10.1378/chest.110.2.325

Corra, U., Piepoli, M. F., Carre, F., Heuschmann, P., Hoffmann, U., Verschuren, M., et al. (2010). Secondary prevention through cardiac rehabilitation: physical activity counselling and exercise training: key components of the position paper from the Cardiac Rehabilitation Section of the European Association of Cardiovascular Prevention and Rehabilitation. Eur. Heart J. 31, 1967-1974. doi: 10.1093/ eurheartj/ehq236 The use of ratings of perceived exertion for exercise prescription in patients receiving beta-blocker therapy. Sports Med. 21, 176-190. doi: 10.2165/00007256-19962103000003

Eston, R. G., and Williams, J. G. (1988). Reliability of ratings of perceived effort regulation of exercise intensity. Br. J. Sports Med. 22, 153-155. doi: 10.1136/bjsm.22.4.153

Faggiano, P., D’Aloia, A., Gualeni, A., Lavatelli, A., and Giordano, A. (1997). Assessment of oxygen uptake during the 6-minute walking test in patients with heart failure: preliminary experience with
Eston, R., and Connolly, D. (1996).

almost all of the patients in our study were under continued $\beta$ blocking medication, and cessation of $\beta$ blockades usually is not possible during exercise tests. Therefore, our results are valid and could be generalized in clinical practice in CAD patients who are under continued $\beta$-blocking medication.

In conclusion, the current study shows that Borg's RPE is a practical tool for assessing $\mathrm{MET}_{\text {peak }}$ in secondary preventive medicine. RPE at submaximal exercise intensity is related to absolute $\mathrm{MET}_{\text {peak }}$ in CAD patients. The data reveal that the relationships between RPE and exercise intensity together with easily measured variables at rest and during "warm-up" exercise can reasonably predict $\mathrm{MET}_{\text {peak }}$ in patients with CAD.

\section{ACKNOWLEDGMENTS}

The authors gratefully acknowledge the assistance of registered nurses Pirkko Huikuri, Päivi Koski, Päivi Kastell, and Sari Kaarlenkaski. The authors appreciate the technical support received from Polar Electro (Kempele, Finland) and HUR Oy (Kokkola, Finland). This study was supported by the Finnish Technology Development Centre (TEKES, Helsinki, Finland) and the Academy of Finland (Helsinki, Finland).

a portable device. Am. Heart J. 134, 203-206. doi: 10.1016/S00028703(97)70125-X

Gayda, M., Temfemo, A., Choquet, D., and Ahmaidi, S. (2004). Cardiorespiratory requirements and reproducibility of the sixminute walk test in elderly patients with coronary artery disease. Arch. Phys. Med. Rehabil. 85, 1538-1543. doi: 10.1016/j.apmr.2003.11.037

Goss, F. L., Robertson, R. J., Haile, L. Nagle, E. F., Metz, K. F., and Kim, K. (2011). Use of ratings of perceived exertion to anticipate treadmill test termination in patients taking beta-blockers. Percept. Mot. Skills 112, 310-318. doi: 10.2466/06. 10.15.PMS.112.1.310-318

Jette, M., Sidney, K., and Blumchen, G. (1990). Metabolic equivalents (METS) in exercise testing, exercise prescription, and evaluation of functional capacity. Clin. Cardiol. 13, 555-565. doi: 10.1002/clc.4960130809

Kavanagh, T., Mertens, D. J., Hamm, L. F., Beyene, J., Kennedy, J., Corey, P., et al. (2002). Prediction of long-term prognosis in 12169 men referred for cardiac rehabilitation. Circulation 106, 666-671. doi: 10.1161/01.CIR.0000024413. 15949.ED

Kavanagh, T., Mertens, D. J., Hamm, L. F., Beyene, J., Kennedy, J., Corey, P., et al. (2003). Peak oxygen intake and cardiac mortality in women referred for cardiac rehabilitation. J. Am. Coll. Cardiol. 42, 2139-2143. doi: 10.1016/j.jacc. 2003.07.028
Lipkin, D. P., Scriven, A. J., Crake, T., and Poole-Wilson, P. A. (1986). Six minute walking test for assessing exercise capacity in chronic heart failure. Br. Med. J. (Clin. Res. Ed.) 292, 653-655. doi: 10.1136/bmj.292.6521.653

Opasich, C., Pinna, G. D., Mazza, A., Febo, O., Riccardi, R., Riccardi, P. G., et al. (2001). Six-minute walking performance in patients with moderate-to-severe heart failure; is it a useful indicator in clinical practice? Eur. Heart J. 22, 488-496. doi: 10.1053/euhj.2000.2310

Perk, J., De Backer, G., Gohlke, H., Graham, I., Reiner, Z., Verschuren, M., et al. (2012). European guidelines on cardiovascular disease prevention in clinical practice (version 2012). the fifth joint task force of the european society of cardiology and other societies on cardiovascular disease prevention in clinical practice (constituted by representatives of nine societies and by invited experts). developed with the special contribution of the european association for cardiovascular prevention and rehabilitation (EACPR). Eur. Heart J. 33, 1635-1701. doi: 10.1093/eurheartj/ehs092

Pollock, M. L., and Pels, A. E. 3rd. (1984). Exercise prescription for the cardiac patient: an update. Clin. Sports Med. 3, 425-442.

Scherr, J., Wolfarth, B., Christle, J. W., Pressler, A., Wagenpfeil, S., and Halle, M. (2013). Associations between Borg's rating of perceived exertion and physiological measures of exercise intensity. Eur. J. 
Appl. Physiol. 113, 147-155. doi: 10.1007/s00421-012-2421-x

Spies, C., Otte, C., Kanaya, A., Pipkin, S. S., Schiller, N. B., and Whooley, M. A. (2005). Association of metabolic syndrome with exercise capacity and heart rate recovery in patients with coronary heart disease in the heart and soul study. Am. J. Cardiol. 95, 1175-1179. doi: 10.1016/j.amjcard.2005.01.045

WHO. (1968). Exercise tests in relation to cardiovascular function. Report of a WHO meeting. World Health Organ. Tech. Rep. Ser. 388, 1-30.

Wijns, W., Kolh, P., Danchin, N., Di Mario, C., Falk, V., Folliguet, T., et al. (2010). Guidelines on myocardial revascularization: the task force on myocardial revascularization of the European Society of Cardiology (ESC) and the European Association for Cardio-Thoracic Surgery (EACTS). Eur. Heart J. 31, 2501-2555. doi: 10.1093/ eurheartj/ehq277

Zugck, C., Kruger, C., Durr, S., Gerber, S. H., Haunstetter, A., Hornig, K., et al. (2000). Is the 6-minute walk test a reliable substitute for peak oxygen uptake in patients with dilated cardiomyopathy? Eur. Heart J. 21, 540-549. doi: 10.1053/euhj. 1999.1861
Conflict of Interest Statement: The authors declare that the research was conducted in the absence of any commercial or financial relationships that could be construed as a potential conflict of interest.

Received: 20 June 2013; accepted: 15 August 2013; published online: 04 September 2013.

Citation: Hautala AJ, Kiviniemi AM, Karjalainen JJ, Piira O-P, Lepojärvi S, Mäkikallio T, Huikuri HV and Tulppo MP (2013) Peak exercise capacity prediction from a submaximal exercise test in coronary artery disease patients. Front. Physiol. 4:243. doi: 10.3389/fphys. 2013.00243
This article was submitted to Clinical and Translational Physiology, a section of the journal Frontiers in Physiology. Copyright (c) 2013 Hautala, Kiviniemi, Karjalainen, Piira, Lepojärvi, Mäkikallio, Huikuri and Tulppo. This is an open-access article distributed under the terms of the Creative Commons Attribution License (CC BY). The use, distribution or reproduction in other forums is permitted, provided the original author(s) or licensor are credited and that the original publication in this journal is cited, in accordance with accepted academic practice. No use, distribution or reproduction is permitted which does not comply with these terms. 